\title{
Evidence for single nucleotide polymorphisms and their association with bipolar disorder
}

\author{
This article was published in the following Dove Press journal: \\ Neuropsychiatric Disease and Treatment \\ 10 October 2013 \\ Number of times this article has been viewed
}

\section{Aleksandra Szczepankiewicz ${ }^{1,2}$ \\ 'Laboratory of Molecular and Cell Biology, ${ }^{2}$ Department of Psychiatric Genetics, Poznan University of Medical Sciences, Poznan, Poland}

\begin{abstract}
Bipolar disorder (BD) is a complex disorder with a number of susceptibility genes and environmental risk factors involved in its pathogenesis. In recent years, huge progress has been made in molecular techniques for genetic studies, which have enabled identification of numerous genomic regions and genetic variants implicated in BD across populations. Despite the abundance of genetic findings, the results have often been inconsistent and not replicated for many candidate genes/single nucleotide polymorphisms (SNPs). Therefore, the aim of the review presented here is to summarize the most important data reported so far in candidate gene and genome-wide association studies. Taking into account the abundance of association data, this review focuses on the most extensively studied genes and polymorphisms reported so far for BD to present the most promising genomic regions/SNPs involved in BD. The review of association data reveals evidence for several genes (SLC6A4/5-HTT [serotonin transporter gene], BDNF [brain-derived neurotrophic factor], DAOA [D-amino acid oxidase activator], DTNBP1 [dysbindin], NRG1 [neuregulin 1],DISC1 [disrupted in schizophrenia 1]) to be crucial candidates in $\mathrm{BD}$, whereas numerous genome-wide association studies conducted in $\mathrm{BD}$ indicate polymorphisms in two genes (CACNA1C [calcium channel, voltage-dependent, L type, alpha $1 C$ subunit], ANK3 [ankyrin 3]) replicated for association with BD in most of these studies. Nevertheless, further studies focusing on interactions between multiple candidate genes/SNPs, as well as systems biology and pathway analyses are necessary to integrate and improve the way we analyze the currently available association data.
\end{abstract}

Keywords: candidate gene, genome-wide association study, SLC6A4, BDNF, DAOA, DTNBP1, NRG1, DISC1

\section{Introduction}

Bipolar disorder (BD) is a common psychiatric illness characterized by recurrent episodes of mania and depression. Heritability, as calculated in recent twin studies, is estimated at about $85 \%,{ }^{1}$ which makes BD one of the most heritable multifactorial medical conditions. It is complex in nature, with underlying numerous susceptibility genes as well as environmental risk factors contributing to heterogeneity in observed clinical phenotypes. Over 20 family studies have demonstrated that the relative risk in the first-degree relatives is seven-fold greater than the risk in general population, whereas twin studies have shown a $70 \%$ concordance rate in monozygotic twins, indicating that the genetic component is very important in the development of BD. Moreover, family studies have indicated common genetic determinants with other psychiatric disorders such as schizophrenia and autism. ${ }^{2,3}$

In the last decades, genetic studies in BD focused on linkage analyses and association studies of candidate genes, resulting in numerous chromosomal regions and gene 
polymorphisms linked to the disease. However, the results so far have been inconsistent across the studies, possibly due to differences between the populations analyzed, limited sample sizes with insufficient power to detect an association, as well as different definitions and descriptions used for the diagnosis of clinical phenotype. Recently, genome-wide association studies (GWASs) have also been applied to discover novel candidates and replicate the findings from previous association analyses of single susceptibility genes.

The aim of this review is to summarize the findings from numerous association studies, focusing on variants within genes that have been widely analyzed and replicated or functionally tested for relevance to the BD phenotype.

\section{Candidate gene studies}

In this approach, a specific gene based on its function is tested for possible involvement in the pathogenesis of disease. Genetic markers of known function or located in potentially important regulatory gene regions are analyzed in case-control studies to determine if the variant is involved in disease. This method enables the detection of variants of physiological relevance using a limited number of statistical tests; however, it is confined to suspected genes with no possibility of identifying novel candidates. A large number of association studies for candidate genes in BD have been performed so far. Some of the candidate genes associated with BD are presented in Table 1.

However, most of these studies present discrepant findings not replicated by others, which makes the interpretation of data difficult. The most consistent associations were observed for a few candidates: SLC6A4/5-HTT (serotonin transporter), BDNF (brain-derived neurotrophic factor), COMT (catecholO-methyltransferase), DISC1 (disrupted in schizophrenia 1, coding for a neuronal growth-related protein), DTNBP1 (dysbindin), DAOA (D-amino acid oxidase activator), and NRG1 (neuregulin 1).

SLC6A4/5-HTT has been one of the most extensively studied in psychiatric diseases. ${ }^{4}$ The transporter plays a crucial role in the active reuptake of serotonin at the synapse that is a known target of selective serotonin reuptake inhibitor antidepressants, which block transporter action. Although numerous studies analyzing its possible association with

Table I Candidate genes most studied in association with bipolar disorder

\begin{tabular}{|c|c|c|c|c|}
\hline Gene symbol & Gene name & Single nucleotide polymorphisms studied & Result & Reference \\
\hline \multirow[t]{2}{*}{ 5-HTT } & Serotonin transporter & $\begin{array}{l}\text { 956304, rs25528, rs6354, rs6355, rs6353, rs6352, } \\
\text { rs } 1042173, \text { rs } 1532042\end{array}$ & $\begin{array}{l}\text { Protective } \\
\text { haplotype }\end{array}$ & 5 \\
\hline & & $\begin{array}{l}\text { rsl050565, rs2020934, rs20667I3, rs2020936, rs2020937, } \\
\text { rs2020938, rs2020939, rsI4070I, rs3794808, rs38I3034 }\end{array}$ & Negative & $6-8$ \\
\hline \multirow[t]{3}{*}{$B D N F$} & Brain-derived & Val/Met $(r s 6265)$ & Positive & $9-17,25$ \\
\hline & neurotrophic factor & Val/Met (rs6265) & $18-23$ & $18-23$ \\
\hline & & $\begin{array}{l}\text { rs988748-(GT)n-rs6265; rs I519480, rs |2273363, } \\
\text { rsII 030107; rs I519480, rs7|27507 rs2030324, rs2883 } 87\end{array}$ & Positive & $17,26,27$ \\
\hline \multirow[t]{3}{*}{ COMT } & Catechol-O- & $\mathrm{Val} / \mathrm{Met}$ & Positive & 36,37 \\
\hline & methyltransferase & $\mathrm{Val} /$ Met & Negative & $29-35$ \\
\hline & & rs737865, rsI65688, rs165599, rs2097603 & Positive & $35,38,39$ \\
\hline \multirow[t]{4}{*}{ DISCI } & $\begin{array}{l}\text { Disrupted in } \\
\text { schizophrenia I }\end{array}$ & 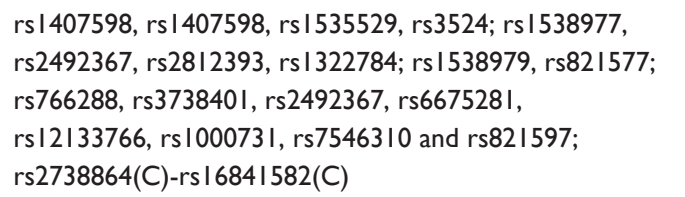 & Positive & $4 \mid-46$ \\
\hline & & A844G, Cl348T, Cl446T, Cl460T, TI595C, Cl4T, & Negative & 47 \\
\hline & & TII870C, GIII60A, CII085A, C948IT, GI9I6A, & & \\
\hline & & T2163A, G2304C, C3215T, G65049 & & \\
\hline DTNBPI & Dysbindin & $\begin{array}{l}\text { rs2619538; PI757 and PI320; rs32I3207, rsI0II3I3, } \\
\text { rs2005976, rs76076I, rs2619522; PI763 }\end{array}$ & Positive & $48-51$ \\
\hline \multirow[t]{2}{*}{$D A O A$} & $\begin{array}{l}\text { D-amino acid oxidase } \\
\text { activator }\end{array}$ & $\begin{array}{l}\text { rs I935058, rsI34I402, rs239II9I, rs I935062, rs947267, } \\
\text { rs95458I; MI2, rs I34I402, MI5 (rs239II9I), rs 1935062, } \\
\text { MI9 (rs778294), M23, M24; rs746I87 (M7), rs39I6966 } \\
\text { (MI3), rs39I6972 (M25); rs746I87-G and rs3916972-G }\end{array}$ & Positive & $54-58$ \\
\hline & & Meta-analysis & Negative & 59 \\
\hline \multirow[t]{4}{*}{ NRGI } & Neuregulin I & SNP8NRG22I533, SNP8NRG24I930, SNP8 & Positive & 61,62 \\
\hline & & NRG243I 77 (rs6994992) & & \\
\hline & & SNP8NRG22I533, 478BI4-878, 420M9-139, SNP8 & Negative & 63 \\
\hline & & NRG243I77, D8SI8I0 & & \\
\hline
\end{tabular}


BD have been performed to date, most of them have focused on the variable number of tandem repeats polymorphism, which has turned out to have functional significance on the transcription initiation of the transporter. Only several association studies including single nucleotide polymorphisms (SNPs) within 5-HTT have been reported so far, but none of these has shown association with BD. ${ }^{5-8}$

Another candidate gene extensively studied in $\mathrm{BD}$ is $B D N F$, a factor involved in brain development - in particular, in the catecholamine system implicated in BD. Its expression is increased on lithium and antidepressant administration. The first described variant includes a functional SNP, Val/Met substitution (rs6265), that affects peptide trafficking and release. Association studies of this functional polymorphism with BD produced inconsistent findings across the populations, with either positive ${ }^{9-17}$ or negative results. ${ }^{18-23}$ The meta-analysis of this substitution has not confirmed the association with BD. ${ }^{24}$ However, another meta-analysis by Fan and Sklar, ${ }^{25}$ based on original published association studies between the Val66Met polymorphism and BD, including 14 studies (4,248 cases and 7,080 control subjects and 858 nuclear families), showed modest but significant evidence for the association of this locus with BD. Some association studies of other SNPs within $B D N F$ (rs6265, rs1519480, rs12273363, rs11030107, rs11030104, rs11030119; haplotype consisting of rs6265 and rs988748; rs1519480, rs7127507) support their role in the pathogenesis of $\mathrm{BD},{ }^{17,26,27}$ but others could not replicate the association of rs6265 and rs11030101 with BD. ${ }^{23}$

COMT is an enzyme involved in monoamine degradation and its gene has been suggested as a candidate for BD. ${ }^{28}$ The most studied polymorphism, Val/Met substitution, which has been shown to influence enzyme activity, has not been confirmed to be associated with $\mathrm{BD}^{29-35}$ except in some studies. ${ }^{36,37}$ However, other polymorphisms (rs165599, rs2097603, Val/Met variant, rs737865) were analyzed with positive results for association with BD..$^{35,38,39}$

Some of the important candidate genes (DISC1, DTNBP1, $D A O A, N R G 1)$ with evidence for association with BD were initially identified by mapping studies in schizophrenia and later also shown to be involved in BD.

DISC1 was identified by mapping a balanced translocation between chromosome 1 and 11 that was found to segregate with both schizophrenia and $\mathrm{BD}$ in a large Scottish pedigree and was the causative mutation in the family. ${ }^{40}$ Further studies supported the association of this gene with BD, both single markers (rs6675281; rs1538979, rs821577; 1030711; rs2492367, rs7546310) and haplotypes (rs7546310A-rs82159T; rs766288A-rs2492367C; rs $1000731 \mathrm{~A}-\mathrm{rs} 7546310 \mathrm{C}$, rs2738864C-rs $16841582 \mathrm{C}$;
rs1030711A-rs751229C-rs1285730A-rs3738401G), ${ }^{41-46}$ except the study by Devon et $\mathrm{al}^{47}$ in which no association of DISC1 polymorphisms (A844G, C1460T, T2163A, and T11870C) with BD was reported.

DTNBP1 is another candidate gene that was reported initially for schizophrenia but has also shown association with BD. The protein is expressed in all neuronal populations of the hippocampus and plays a role in glutamatergic pathway signaling. The association of single polymorphisms (rs2005976, rs760761; rs2619522) and haplotypes (rs3213207Ars1011313C-rs2005976G-rs760761 T-rs2619522A; TCGG and GTAA of SNPs: rs2619522, rs760761, rs2005976, rs2619528; rs2619538-rs2619522) has been supported by several positive studies. ${ }^{48-51}$

$D A O A$ (G72/G30) was first identified by linkage family studies to chromosome $13 \mathrm{q}$, a region also linked to BD. ${ }^{52,53}$ A number of studies showed positive association with BD (rs1935058; rs1341402, rs1935062, rs778294; rs947267; haplotypes: rs2111902A-rs3918346T and rs746187Grs3916972G; haplotypes: CGCAT, TAACT, CGACT, TGCAT of five SNPs: rs1935058, rs2391191, rs1935062, rs947267, rs954581). ${ }^{54-57}$ Further evidence was reported in a large study analyzing nine polymorphisms that tag the common genetic variations in $D A O A$ in association with susceptibility to mood episodes in BD (rs391695, rs1341402, DAOA_3'UTR_SNP12). ${ }^{58}$ However, associations of the studied DAOA polymorphisms (rs2391191G, rs778294T, rs1341402T, rs1935058C, and rs1935062C) were not confirmed in a meta-analysis by Shi et al. ${ }^{59}$

$N R G 1$ interacts with ErbB4 to regulate glutamate signaling via the N-methyl-D-aspartate receptor. The gene was first identified by linkage to chromosome $8 \mathrm{p}$ in Icelandic families with schizophrenia, ${ }^{60}$ followed by association of this gene with BD (single markers: SNP8NRG221533; rs553950, rs327329, rs7007662; haplotypes: NP8NRG221533-rs4298458SNP8NRG241930-SNP8NRG243177; rs2919390rs6988339-rs3757930). ${ }^{61,62}$ However, this was not replicated in an Irish trios study (SNP8NRG221533, 478B14-878, 420M9-139, SNP8NRG243177). ${ }^{63}$

\section{GWASs}

This method involves the simultaneous analysis of hundreds of SNPs distributed throughout the genome in large cohorts of patients and controls to identify genetic markers associated with the disease. In contrast to most candidate gene studies, GWASs are well powered and the genes found are usually replicated in other studies, demonstrating their priority over candidate gene studies. In $\mathrm{BD}$, the first such study was published by the Wellcome Trust Case Control 
Consortium (WTCCC) in 2007. The study included about 2,000 bipolar cases and 3,000 controls and analysis of 500,000 SNPs revealed that the region with the strongest evidence for association with $\mathrm{BD}$ was at locus $16 \mathrm{p} 12$ $\left(P=10^{-8}\right)$, which contains three genes of potential pathological relevance to $\mathrm{BD}$ (PALB2 [partner and localizer of BRCA2], NDUFAB1 [NADH dehydrogenase (ubiquinone) 1], DCTN5 [dynactin 5]). ${ }^{41}$ Another GWAS was performed by Sklar et $\mathrm{al}^{64}$ on the sample for the Systematic Treatment Enhancement Program for Bipolar Disorder (STEP-BD), a large treatment study in BD. This analysis identified two genes, MYO5B (myosin 5B) and TSPAN8 (tetraspanin-8), associated with BD, although this finding was not replicated in an independent sample.

The gene that showed evidence for association in both those studies was $C A C N A 1 C$, a member of a family of L-type calcium channels. This candidate gene was also identified in a combined analysis study, by Ferreira et al, ${ }^{65}$ of the two aforementioned datasets and additional samples for a total of 4,387 cases and 6,209 controls. This study also identified another candidate with the strongest evidence for association with BD: the ANK3 (ankyrin 3) gene encoding ankyrin G, a cytoskeletal protein expressed in the brain and involved in attaching sodium channels to the cytoskeleton.

A later GWAS performed by Smith et $\mathrm{al}^{66}$ of a National Institute of Mental Health (NIMH) Genetics Initiative for Bipolar Disorder sample, a part of the Bipolar Genome Study (BiGS), failed to identify any SNP with a genome-wide significance; however, they showed suggestive evidence for association of the following candidate genes: NAP5 (NCK-associated protein 5), DPY19L3 (dpy-19-like 3 [Caenorhabditis elegans]), and NTRK2 (neurotrophic tyrosine kinase receptor type 2). In particular, the latter gene is a good candidate, encoding the Trkb tyrosine kinase receptor for BDNF that has been extensively studied in psychiatric disorders. The study by Smith et al is also one of the few that has examined a non-Caucasian population. Combined analysis of European-American and African-American samples enabled identification of several genes showing association in both populations, but with different alleles (ROR1 [receptor tyrosine kinase-like orphan receptor 1], RGS5 [regulator of $G$ protein signaling 5], BTBD16 [BTB (POZ) domain containing 16]), suggesting that alternative variants in the same genes predispose to BD depending on the population.

Similar to this study, no significant evidence for association was observed in a GWAS by Scott et $\mathrm{a}^{67}$ in three populations of 3,683 Caucasian cases and 14,507 controls. The SNPs with suggestive evidence for association included the following genes: ITIH1 (inter-alpha-trypsin inhibitor heavy chain 1), GNL3 (guanine nucleotide binding protein-like 3), NEK4
(NIMA-related kinase 4), and ITIH3 (inter-alpha-trypsin inhibitor heavy chain 3), as well as replication for $A N K 3$ gene.

A later study undertaken by the Psychiatric GWAS Consortium Bipolar Disorder Working Group ${ }^{68}$ published a combined GWAS of 11,974 bipolar patients and 51,792 controls as part of the Psychiatric GWAS Consortium. In that study, genome-wide significant evidence of association for $C A C N A 1 C$ was confirmed and for the identification of a new intronic variant in $O D Z 4$ gene presented.

A novel genetic variation (rs1064395) within the $N C A N$ (neurocan) gene that showed genome-wide significant association $\left(P=3.02 \times 10^{-8}\right)$ was identified in a combined GWAS and first follow-up step study performed in 2,411 BD patients and 3,613 controls. ${ }^{69}$ This finding was replicated in a second follow-up step study (6,030 patients and 31,749 controls; $\left.P=2.74 \times 10^{-4}\right)$. The combined analysis of all study samples yielded a $P$-value of $2.14 \times 10^{-9}$, providing evidence that rs 1064395 is a common risk factor for BD. NCAN encodes neurocan, an extracellular matrix glycoprotein involved in cell adhesion and migration, with expression localized within cortical and hippocampal areas involved in cognition and emotion regulation implicated in BD.

The most recent GWAS by Green et $\mathrm{al}^{70}$ of an independent UK sample of 1,218 BD cases and 2,913 controls replicated previous findings by Ferreira et $\mathrm{al}^{65}$ for two of the three most strongly associated chromosomal regions in the study, $C A C N A 1 C$ (rs1006737, $P=4.09 \times 10^{-4}$ ) and $15 q 14$ (rs2172835, $P=0.043$ ), but not $A N K 3$ (rs10994336, $P=0.912$ ). Moreover, the authors performed combined analysis of two populations, ImmunoChip data (569 quasiindependent SNPs from the 3,016 SNPs genotyped) with the recently published Psychiatric Genome-Wide Association Study Consortium Bipolar Disorder Working Group (PGC-BD) meta-analysis data and found two novel variants associated with BD: rs7296288 $\left(P=8.97 \times 10^{-9}\right)$, an intergenic polymorphism on chromosome 12 located between RHEBL1 (Ras homolog enriched in brain like 1) and $\mathrm{DHH}$ (desert hedgehog), and rs3818253 ( $\left.P=3.88 \times 10^{-8}\right)$, an intronic SNP on chromosome 20q11.2 in the TRPC4AP (transient receptor potential cation channel, subfamily $C$, member 4 associated protein) gene, which lies in a high linkage disequilibrium region along with the genes GSS (glutathione synthetase) and $M Y H 7 B$ (myosin heavy chain 7B).

A few national GWASs have also been performed. Among others, one in a Bulgarian population ${ }^{71}$ and two in Scandinavian populations - one Swedish ${ }^{72}$ and the other Norwegian - followed by replication in an Icelandic population; ${ }^{73}$ all of these failed to identify any locus of genome-wide significance for association with BD. However, 
in the Bulgarian study, the authors mentioned three variants with possible involvement in BD: $r 8099939\left(P=2.12 \times 10^{-6}\right)$ in the GRIK5 (glutamate receptor, ionotropic, kainate 5) gene, rs6122972 $\left(P=3.11 \times 10^{-6}\right)$ in the PARD6B (par-6 family cell polarity regulator beta) gene, and rs2289700 $\left(P=9.14 \times 10^{-6}\right)$ in the CTSH (cathepsin H) gene. ${ }^{71}$

Two GWASs in Asian populations have been performed: one by Hattori et $\mathrm{al}^{74}$ in a Japanese population of 107 cases and 107 controls, and the other by Lee et $\mathrm{al}^{75}$ in a Han Chinese population of 1,000 bipolar I patients and 1,000 controls. In both studies, none of the SNPs was associated with BD at genome-wide significance. A summary of GWASs is presented in Table 2.

Recently, the Cross-Disorder Group of the Psychiatric Genomics Consortium published GWAS results for five major psychiatric disorders - autism spectrum disorder, attention deficit-hyperactivity disorder, BD, major depressive disorder, and schizophrenia - to identify loci shared between those disorders. ${ }^{76}$ The analysis of 33,332 cases and 27,888 controls revealed that genome-wide significance $\left(P<5 \times 10^{-8}\right)$ was reached for regions on chromosomes 3p21 and 10q24 and SNPs within two L-type voltage-gated calcium-channel subunits, CACNA1C and CACNB2 (calcium channel, voltagedependent, beta 2 subunit), indicating that specific SNPs are associated with a range of psychiatric disorders and that variation in calcium-channel activity genes may exert pleiotropic effects on the psychopathology of psychiatric genetics.

The results from GWASs provide numerous SNPs evidenced for association with $\mathrm{BD}$, with the strongest confirmation of two loci, $C A C N A 1 C$ and $A N K 3$. However, lack of consistent findings throughout the studies, possibly due to insufficient power to detect associations with genes of small effects, impede drawing conclusions. Recently, a meta-analysis of GWASs and all published candidate gene-association studies of BD (a total of 487 articles) was published to evaluate the cumulative evidence of associations observed so far. ${ }^{77}$ Polymorphisms in $B D N F, D R D 4, D A O A$, and TPHI (tryptophan hydroxylase 1) were found to be nominally

Table 2 Genome-wide association studies (GWASs) in bipolar disorder

\begin{tabular}{|c|c|c|c|c|c|}
\hline Sample & Population & Type & Sample size & Result & Study \\
\hline WTCCC & Caucasian & Case control & $2,000 / 3,000$ & $16 p \mid 2(P A L B 2)$ & 41 \\
\hline \multirow[t]{2}{*}{ STEP-BD } & Caucasian & Case control & $\mathrm{I}, 46 \mathrm{I} / 2,008$ & rs493992I (MYO5B) & 64 \\
\hline & & & & rs I 705236 (TSPAN8) & \\
\hline \multirow[t]{2}{*}{ WTCCC + STEP-BD } & Caucasian & Meta-analysis & $4,387 / 6,209$ & rs I 006737 (CACNAIC) & 65 \\
\hline & & & & rs 10994336 (ANK3) & \\
\hline \multirow[t]{4}{*}{ BiGS (NIMH) } & European-American & Case control & $\mathrm{I}, 00 \mathrm{I} / \mathrm{I}, 033$ & rs5907577 (Xq27.I) & 66 \\
\hline & & & & rs I019387I (NAP5) & \\
\hline & African-American & Case control & $345 / 670$ & rs2III504 (DPYI9L3) & 66 \\
\hline & & & & rs2769605 (NTRK2) & \\
\hline \multirow[t]{4}{*}{ NIMH/Pritzker GSK WTCCC } & Caucasian & Pooling; individual & $3,683 / 14,507$ & Ip3I.I & 67 \\
\hline & & genotyping & & $3 p 21$ & \\
\hline & & & & MCTPI & \\
\hline & & & & rs I $042779(I T I H I)$ & \\
\hline GWAS Consortium Bipolar & Caucasian & & II,974/5।,792 & rs47659I3 (CACNAIC) & 68 \\
\hline Disorder Working Group & & & & rs $12576775(O D Z 4)$ & \\
\hline German sample, Replication I and II & Caucasian & Case-control pooling & $8,44 I / 35,362$ & rsI064395 (NCAN) & 69 \\
\hline UK sample & Caucasian & Case control; & $1,218 / 2,9 \mid 3$ & rs I 006737 (CACNAIC) & 70 \\
\hline \multirow[t]{4}{*}{ ImmunoChip data + PGC-BD } & & Meta-analysis & & rs2172835 (I5q/4) & \\
\hline & & & & rs7296288 (between & \\
\hline & & & & RHEBLI and $D H H)$ & \\
\hline & & & & rs38I8253 (TRPC4AP) & \\
\hline \multirow[t]{3}{*}{ Bulgarian } & Caucasian & Case control & $188 / 376$ & rs8099939 (GRIK5) & 71 \\
\hline & & & & rs6I22972 (PARD6B) & \\
\hline & & & & rs2289700 (CTSH) & \\
\hline Swedish & Caucasian & Case control & $836 / 2,093$ & None & 72 \\
\hline \multirow{2}{*}{ Norwegian Icelandic } & Caucasian & Case control & $194 / 336$ & rs4377455 (BMS3) & 73 \\
\hline & & & $435 / 10,258$ & & \\
\hline Japanese & Asian & Case control & $107 / 107$ & None & 74 \\
\hline \multirow[t]{3}{*}{ Han Chinese } & Asian & Case control & $I, 000 / I, 000$ & rs2709736, rs8040009 (ST8SIA2) & 75 \\
\hline & & & & rs207383I (KCTD/2) & \\
\hline & & & & rs II0I3860 (CACNB2) & \\
\hline
\end{tabular}

Abbreviations: BiGS, Bipolar Genome Study; GSK, GlaxoSmithKline; NIMH, National Institute of Mental Health; PGC-BD, Psychiatric Genome-Wide Association Study Consortium Bipolar Disorder Working Group; STEP-BD, Systematic Treatment Enhancement Program for Bipolar Disorder; WTCCC, Wellcome Trust Case Control Consortium. 
significant; however, none of these findings was significant after correction for multiple testing. Moreover, none of these polymorphisms was significant in the Psychiatric GWAS Consortium Bipolar Disorder study. ${ }^{76}$

\section{Phenotypes related to BD}

Taking into account the genetic heterogeneity of BD, it has been suggested that clinical phenotypes may be more useful in delineating the genetic variants contributing to $\mathrm{BD}$ than standard diagnostic models. ${ }^{78}$ Clinical sub-phenotypes of BD may identify more homogeneous subsets of patients who can be studied with increased power to detect genetic variation. To date, several studies have applied this concept to data from GWASs.

In a GWAS of BD patients with seasonal patterned mania (seasonal or non-seasonal patterned manic episodes), the most significant association was observed for rs41350144, which lies within an intron of the NF1A (nuclear factor I/A) gene on $1 \mathrm{p} 31\left(P=3.08 \times 10^{-7}\right)$, suggesting it may predispose to this subtype of BD. ${ }^{79}$

A GWAS of mood-incongruent psychotic features in bipolar patients $(2,196$ cases with mood-incongruent psychotic features and 8,148 controls) revealed no association of genome-wide significance; however, several regions with suggestive evidence of association $\left(P<10^{-6}\right)$ were found: 6q14.2 within the PRSS35 (protease serine 35)/ SNAP91 (synaptosomal-associated protein) gene complex (rs1171113, $P=9.67 \times 10^{-8}$ ), 3p22.2 downstream of TRANK/ $L B A 1$ (tetratricopeptide repeat and ankyrin repeat containing 1) ( $\left.\mathrm{rs} 9834970, P=9.71 \times 10^{-8}\right)$, and $14 \mathrm{q} 24.2$ in an intron of numb homolog (Drosophila) (rs2333194, $\left.P=7.03 \times 10^{-7}\right){ }^{80}$

In a GWAS of factor dimensions in 927 clinically wellcharacterized BD patients of German ancestry, the authors found that the factor dimension "negative mood delusions" was significantly associated with one variant (rs9875793; $\left.\mathrm{n}=927 ; P=4.65 \times 10^{-8}\right) .{ }^{81}$ This SNP is located in an intergenic region of $3 \mathrm{q} 26.1$ in the proximity of the SLC2A2 (solute carrier family 2 [facilitated glucose transporter], member 2) gene. In case-control analyses, significant association with the G allele of rs9875793 was only observed in the subgroup of 89 BD patients who displayed symptoms of negative mood delusions. Further support for the association of rs9875793 with BD in patients displaying the negative mood delusions symptom was obtained from an European-American sample of 1,247 BD patients and 1,434 controls.

The study that first tested bipolar patients according to age-at-onset (AAO) subgroups was performed by Dizier et $\mathrm{al}^{82}$ in a sample of 443 unrelated bipolar patients and 1,731 controls. The study provided evidence for genetic variation within the $A D R B 2$ ( $\beta_{2}$-adrenoreceptor) gene region that is specifically associated with the early onset form of BD. However, this finding could not be replicated in the WTCCC sample due to poor genotyping coverage of the $A D R B 2$ gene (the SNPs that showed the strongest signal for association in the study were not available in the WTCCC sample and were not in LD (linkage disequilibrium) with the SNPs available in the replication sample). Therefore, the finding requires further investigation.

A meta-analysis of two widely studied sub-phenotypes of $\mathrm{BD}, \mathrm{AAO}$ and psychotic symptoms, which are familial and clinically significant, was conducted by Belmonte Mahon et al ${ }^{83}$ on combined data from three GWASs: the NIMH Bipolar Disorder Genetic Association Information Network (GAINBP), NIMH BiGS, and a German sample, with a total of 2,836 BD cases with information on sub-phenotypes and 2,744 controls. No SNP reached genome-wide significance for either sub-phenotype. The same results were observed in a meta-analysis with an independent replication sample. This indicates that $\mathrm{AAO}$ and psychotic symptoms in BD may be influenced by other variants not measured well by SNP arrays, such as rare alleles.

Family and twin studies suggest that susceptibility for suicide attempts is heritable and distinct from mood disorder susceptibility, and the high resolution of the GWAS approach facilitates the detection of risk loci. The first GWAS performed for lifetime suicide attempts sub-phenotype was conducted by Perlis et al. ${ }^{84} \mathrm{BD}$ subjects were drawn from the Systematic Treatment Enhancement Program for Bipolar Disorder cohort, the WTCCC bipolar cohort, and the University College London cohort. Replication was pursued in the NIMH Genetic Association Information Network BD project and a German clinical cohort. The strongest evidence of association for suicide attempts in BD was observed in a region without identified genes (rs1466846) and five loci showed suggestive evidence of association.

Another attempted suicide GWAS that compared the SNP genotypes of 1,201 BD subjects with a history of suicide attempts to the genotypes of 1,497 BD subjects without a history of suicide attempts was performed by Willour et al. ${ }^{85}$ The authors found 2,507 SNPs with evidence for association with suicide attempts at $P<0.001$, but these associations were not significantly associated in the replication sample after correcting for multiple testing. However, the combined analysis of the two sample sets produced an association signal on 2p25 (rs300774) at the threshold of genome-wide significance $\left(P=5.07 \times 10^{-8}\right)$. This variant is located in a large linkage disequilibrium block containing the ACP1 (acid phosphatase 1) gene, the expression of which 
is significantly elevated in $\mathrm{BD}$ subjects who have completed suicide. The results of both GWASs suggest that inherited risk for suicide among bipolar patients is unlikely to be the result of individual common variants of large effects.

A GWAS testing comorbidities in BD (BD with psychosis and/or substance abuse in the absence of alcohol dependence) showed association with the rare variant (rs1039002) in the vicinity of the PDE10A (phosphodiesterase $10 A)$ gene $\left(P=1.7 \times 10^{-8}\right)$, which was implicated in the pathophysiology of psychosis. Another rare variant, rs 12563333 on chromosome 1q41 close to the MARK1 (MAP/microtubule affinity-regulating kinase 1) gene, demonstrated an almost genome-wide level of significance in this subgroup $\left(P=5.9 \times 10^{-8}\right)$. Homozygotes for the minor allele were present in cases and absent in controls. BD with alcohol dependence and other comorbidities was associated with SNP rs2727943 $\left(P=3.3 \times 10^{-8}\right)$ on chromosome 3p26.3 located between the genes $B I G-2$ (contactin-4 precursor) and CNTN6 (contactin 6). BD with low probability of comorbid conditions did not show significant associations. ${ }^{86}$

Neuroimaging is commonly used to characterize brain activity that is altered in psychiatric disorders including $\mathrm{BD}$. By use of functional magnetic resonance imaging, it was found that amygdala activation during a face-processing task differs between bipolar patients and healthy controls ${ }^{87}$ In a GWAS, a SNP (rs2023454) in DOK5 (docking protein 5) gene involved in the neurotrophin signaling pathway was found to be associated with right amygdala activation. ${ }^{88}$ Another GWAS performed on neurocognition in $157 \mathrm{BD}$ patients and 353 controls $^{89}$ identified three intronic SNPs in the PTPRO (protein tyrosine phosphatase receptor type $O$ ) gene associated with learning and memory (rs17222089, rs11056571, and rs2300290) and rs719714 near WDR72 (WD repeat domain 72) associated with executive functioning as well as highly significant interaction between FOXQ1 (forkhead box Q1) and SUMOIP1 (SUMO1 pseudogene 1) SNPs for psychomotor speed.

Several studies analyzing the influence of variation in candidate genes for $\mathrm{BD}$ on neuroanatomy and neurocognition have also been performed. A SNP in the CACNA1C gene (rs1006737) previously associated with BD in several GWASs, was also found related to alterations in structural and functional magnetic resonance imaging, with A allele associated with increased gray-matter volume and reduced functional connectivity within the cortico-limbic frontotemporal neural system, ${ }^{90}$ as well as worsened performance of executive function tests in BD patients. ${ }^{91}$ However, it was not associated with spatial working memory in BD patients. ${ }^{92}$ Evidence for the involvement of SNPs within the DISC1 gene, another strong candidate for $\mathrm{BD}$, in neuroanatomy and neurocognition was provided by Carless et al. ${ }^{93}$ Recently, a study by $\mathrm{Li}$ et al ${ }^{14}$ analyzing SNPs in CREB1 (cAMP responsive element binding protein 1) gene in $\mathrm{BD}$ patients of European ancestry, reported a significant association of risk SNPs with a decreased hippocampal volume and diminished activation of the left hippocampus, further suggesting their involvement in BD susceptibility.

\section{Conclusion}

The results from candidate gene association studies and GWASs have provided some findings for BD and indicated a number of genes and variants involved. However, inconsistency between studies, as well as only modest replication of variants identified for BD by independent analyses - in particular, in the case of candidate gene studies - impede drawing conclusions. The discrepancies in candidate gene studies may partly result from the clinical and genetic heterogeneity of $\mathrm{BD}$ and its complex inheritance model but also from methodological issues such as the definition of clinical phenotype.

Further, it should also be taken into account that although many genes/risk alleles are implicated in BD, the individual effect sizes of each allele contribute to only a small fraction $(\sim 3 \%)$ of the total population variance. ${ }^{95}$ Despite the high estimated heritability of $\mathrm{BD}$, the thousands of markers analyzed by GWASs explain only about $5 \%$ of phenotypic variance, despite studies of tens of thousands of people. As such, much of the heritability of BD has been missed by GWAS findings so far. The possible explanations of this missing heritability include analysis of rare variants (according to the "common disease-multiple rare variants" hypothesis); analysis of structural genomic variants, termed "copy number variants," with higher odds ratios than common variants (SNPs); as well as the functional characterization of specific SNPs, such as their effects on gene expression or DNA methylation. Nextgeneration sequencing offers help in elucidating if the missing heritability is due to missed genetic associations. Moreover, taking into account the polygenic inheritance of $\mathrm{BD}$, with a large number of markers with small individual effects collectively accounting for disease risk, novel approaches including systems biology and pathway analysis may be helpful in identifying functional interactions between multiple genes involved in the pathophysiology of BD. These methods are already being used in ongoing experiments ${ }^{96-98}$ to determine the underlying mechanisms and identify causal variants for this disease.

Thus, the genetic findings in $\mathrm{BD}$, although promising, are far from being translated into clinical practice.

\section{Disclosure}

The author declares no conflicts of interest in this work. 


\section{References}

1. Bienvenu OJ, Davydow DS, Kendler KS. Psychiatric 'diseases' versus behavioral disorders and degree of genetic influence. Psychol Med. 2011;41(1):33-40.

2. Lichtenstein P, Yip BH, Björk C, et al. Common genetic determinants of schizophrenia and bipolar disorder in Swedish families: a populationbased study. Lancet. 2009;373(9659):234-239.

3. Sullivan PF, Magnusson C, Reichenberg A, et al. Family history of schizophrenia and bipolar disorder as risk factors for autism. Arch Gen Psychiatry. 2012;69(11):1099-1103.

4. Caspi A, Hariri AR, Holmes A, Uher R, Moffitt TE. Genetic sensitivity to the environment: the case of the serotonin transporter gene and its implications for studying complex diseases and traits. Am J Psychiatry. 2010;167(5):509-527.

5. Sun HS, Wang HC, Lai TJ, Wang TJ, Li CM. Sequence variants and haplotype analysis of serotonin transporter gene and association with bipolar affective disorder in Taiwan. Pharmacogenetics. 2004;14(3): $173-179$.

6. Ikeda M, Iwata N, Suzuki T, et al. No association of serotonin transporter gene (SLC6A4) with schizophrenia and bipolar disorder in Japanese patients: association analysis based on linkage disequilibrium. J Neural Transm. 2006;113(7):899-905.

7. Mansour HA, Talkowski ME, Wood J, et al. Serotonin gene polymorphisms and bipolar I disorder: focus on the serotonin transporter. Ann Med. 2005;37(8):590-602.

8. Alaerts M, Ceulemans S, Forero D, et al. Detailed analysis of the serotonin transporter gene (SLC6A4) shows no association with bipolar disorder in the Northern Swedish population. Am J Med Genet B Neuropsychiatr Genet. 2009;150B(4):585-592.

9. Sklar P, Gabriel SB, McInnis MG, et al. Family-based association study of 76 candidate genes in bipolar disorder: BDNF is a potential risk locus. Brain-derived neutrophic factor. Mol Psychiatry. 2002;7(6): 579-593.

10. Neves-Pereira M, Mundo E, Muglia P, King N, Macciardi F, Kennedy JL. The brain-derived neurotrophic factor gene confers susceptibility to bipolar disorder: evidence from a family-based association study. Am J Hum Genet. 2002;71(3):651-655.

11. Lohoff FW, Sander T, Ferraro TN, Dahl JP, Gallinat J, Berrettini WH. Confirmation of association between the Val66Met polymorphism in the brain-derived neurotrophic factor (BDNF) gene and bipolar I disorder. Am J Med Genet B Neuropsychiatr Genet. 2005;139B(1): 51-53.

12. Green EK, Raybould R, Macgregor S, et al. Genetic variation of brain-derived neurotrophic factor (BDNF) in bipolar disorder: casecontrol study of over 3000 individuals from the UK. Br J Psychiatry. 2006;188:21-25.

13. Okada T, Hashimoto R, Numakawa T, et al. A complex polymorphic region in the brain-derived neurotrophic factor (BDNF) gene confers susceptibility to bipolar disorder and affects transcriptional activity. Mol Psychiatry. 2006;11(7):695-703.

14. Kremeyer B, Herzberg I, Garcia J, et al. Transmission distortion of BDNF variants to bipolar disorder type I patients from a South American population isolate. Am JMed Genet B Neuropsychiatr Genet. 2006;141B(5):435-439.

15. Xu J, Liu Y, Wang P, et al. Positive association between the brainderived neurotrophic factor (BDNF) gene and bipolar disorder in the Han Chinese population. Am J Med Genet B Neuropsychiatr Genet. 2010;153B(1):275-279.

16. Wang Z, Li Z, Chen J, et al. Association of BDNF gene polymorphism with bipolar disorders in Han Chinese population. Genes Brain Behav. 2012;11(5):524-528.

17. Sears C, Markie D, Olds R, Fitches A. Evidence of associations between bipolar disorder and the brain-derived neurotrophic factor (BDNF) gene. Bipolar Disord. 2011;13(7-8):630-637.

18. Nakata K, Ujike H, Sakai A, et al. Association study of the brain-derived neurotrophic factor (BDNF) gene with bipolar disorder. Neurosci Lett. 2003;337(1):17-20.
19. Hong CJ, Liu HC, Liu TY, Lin CH, Cheng CY, Tsai SJ. Brain-derived neurotrophic factor (BDNF) Val66Met polymorphisms in Parkinson's disease and age of onset. Neurosci Lett. 2003;353(1):75-77.

20. Kunugi H, Ueki A, Otsuka M, et al. A novel polymorphism of the brainderived neurotrophic factor (BDNF) gene associated with late-onset Alzheimer's disease. Mol Psychiatry. 2001;6(1):83-86.

21. Skibinska M, Hauser J, Czerski PM, et al. Association analysis of brainderived neurotrophic factor (BDNF) gene Val66Met polymorphism in schizophrenia and bipolar affective disorder. World J Biol Psychiatry. 2004;5(4):215-220.

22. Neves-Pereira M, Cheung JK, Pasdar A, et al. BDNF gene is a risk factor for schizophrenia in a Scottish population. Mol Psychiatry. 2005;10(2): 208-212.

23. Ye CY, Xu YQ, Hu H, et al. An association study of brain-derived neurotrophic factor gene polymorphism in bipolar disorders. Zhonghua Yi Xue Za Zhi. 2009;89(27):1897-1901. Chinese.

24. Kanazawa T, Glatt SJ, Kia-Keating B, Yoneda H, Tsuang MT. Metaanalysis reveals no association of the Val66Met polymorphism of brain-derived neurotrophic factor with either schizophrenia or bipolar disorder. Psychiatr Genet. 2007;17(3):165-170.

25. Fan J, Sklar P. Genetics of bipolar disorder: focus on BDNF Val66Met polymorphism. Novartis Found Symp. 2008;289:60-72; discussion 72-73, 87-93

26. Schumacher J, Jamra RA, Becker T, et al. Evidence for a relationship between genetic variants at the brain-derived neurotrophic factor (BDNF) locus and major depression. Biol Psychiatry. 2005;58(4): 307-314.

27. Liu L, Foroud T, Xuei X, et al. Evidence of association between brainderived neurotrophic factor gene and bipolar disorder. Psychiatr Genet. 2008;18(6):267-274.

28. Craddock N, Owen MJ, O’Donovan MC. The catechol-O-methyl transferase (COMT) gene as a candidate for psychiatric phenotypes: evidence and lessons. Mol Psychiatry. 2006;11(5):446-458.

29. Gutiérrez B, Bertranpetit J, Guillamat R, et al. Association analysis of the catechol O-methyltransferase gene and bipolar affective disorder. Am J Psychiatry. 1997;154(1):113-115.

30. No association between bipolar disorder and alleles at a functional polymorphism in the COMT gene. Biomed European Bipolar Collaborative Group. Br J Psychiatry. 1997;170:526-528.

31. Lachman HM, Kelsoe J, Moreno L, Katz S, Papolos DF. Lack of association of catechol-O-methyltransferase (COMT) functional polymorphism in bipolar affective disorder. Psychiatr Genet. 1997;7(1): 13-17.

32. Kirov G, Jones I, McCandless F, Craddock N, Owen MJ. Family-based association studies of bipolar disorder with candidate genes involved in dopamine neurotransmission: DBH, DAT1, COMT, DRD2, DRD3 and DRD5. Mol Psychiatry. 1999;4(6):558-565.

33. Kunugi H, Vallada HP, Hoda F, et al. No evidence for an association of affective disorders with high- or low-activity allele of catechol-omethyltransferase gene. Biol Psychiatry. 1997;42(4):282-285.

34. Serretti A, Rotondo A, Lorenzi C, Smeraldi E, Cassano GB. CatecholO-methyltransferase gene variants in mood disorders in the Italian population. Psychiatr Genet. 2006;16(5):181-182.

35. Burdick KE, Funke B, Goldberg JF, et al. COMT genotype increases risk for bipolar I disorder and influences neurocognitive performance. Bipolar Disord. 2007;9(4):370-376.

36. Li T, Vallada H, Curtis D, et al. Catechol-O-methyltransferase Val158Met polymorphism: frequency analysis in Han Chinese subjects and allelic association of the low activity allele with bipolar affective disorder. Pharmacogenetics. 1997;7(5):349-353.

37. Mynett-Johnson LA, Murphy VE, Claffey E, Shields DC, McKeon P. Preliminary evidence of an association between bipolar disorder in females and the catechol-O-methyltransferase gene. Psychiatr Genet. 1998;8(4):221-225.

38. Shifman S, Bronstein M, Sternfeld M, et al. COMT: a common susceptibility gene in bipolar disorder and schizophrenia. Am J Med Genet B Neuropsychiatr Genet. 2004;128B(1):61-64. 
39. Funke B, Malhotra AK, Finn CT, et al. COMT genetic variation confers risk for psychotic and affective disorders: a case control study. Behav Brain Funct. 2005;1:19.

40. Blackwood DH, Fordyce A, Walker MT, St Clair DM, Porteous DJ, Muir WJ. Schizophrenia and affective disorders - cosegregation with a translocation at chromosome $1 \mathrm{q} 42$ that directly disrupts brainexpressed genes: clinical and P300 findings in a family. Am J Hum Genet. 2001;69(2):428-433.

41. Wellcome Trust Case Control Consortium. Genome-wide association study of 14,000 cases of seven common diseases and 3,000 shared controls. Nature. 2007;447(7145):661-678.

42. Hodgkinson CA, Goldman D, Jaeger J, et al. Disrupted in schizophrenia 1 (DISC1): association with schizophrenia, schizoaffective disorder, and bipolar disorder. Am J Hum Genet. 2004;75(5):862-872.

43. Thomson PA, Wray NR, Millar JK, et al. Association between the TRAX/DISC locus and both bipolar disorder and schizophrenia in the Scottish population. Mol Psychiatry. 2005;10(7):657-668, 616.

44. Hennah W, Thomson P, McQuillin A, et al. DISC1 association, heterogeneity and interplay in schizophrenia and bipolar disorder. $\mathrm{Mol}$ Psychiatry. 2009;14(9):865-873.

45. Schosser A, Gaysina D, Cohen-Woods S, et al. Association of DISC1 and TSNAX genes and affective disorders in the depression casecontrol (DeCC) and bipolar affective case-control (BACCS) studies. Mol Psychiatry. 2010;15(8):844-849.

46. Xiao Y, Zhang J, Wang Y, et al. Limited association between Disrupted in Schizophrenia 1 (DISC1) gene and bipolar disorder in the Chinese population. Psychiatr Genet. 2011;21(1):42-46.

47. Devon RS, Anderson S, Teague PW, et al. Identification of polymorphisms within Disrupted in Schizophrenia 1 and Disrupted in Schizophrenia 2, and an investigation of their association with schizophrenia and bipolar affective disorder. Psychiatr Genet. 2001;11(2):71-78.

48. Raybould R, Green EK, MacGregor S, et al. Bipolar disorder and polymorphisms in the dysbindin gene (DTNBP1). Biol Psychiatry. 2005;57(7):696-701.

49. Breen G, Prata D, Osborne S, et al. Association of the dysbindin gene with bipolar affective disorder. Am J Psychiatry. 2006;163(9):1636-1638.

50. Pae CU, Serretti A, Mandelli L, et al. Effect of 5-haplotype of dysbindin gene (DTNBP1) polymorphisms for the susceptibility to bipolar I disorder. Am J Med Genet B Neuropsychiatr Genet. 2007;144B(5): 701-703.

51. Joo EJ, Lee KY, Jeong SH, et al. Dysbindin gene variants are associated with bipolar I disorder in a Korean population. $\mathrm{Neurosci}$ Lett. 2007;418(3):272-275.

52. Detera-Wadleigh SD, Badner JA, Berrettini WH, et al. A high-density genome scan detects evidence for a bipolar-disorder susceptibility locus on 13q32 and other potential loci on 1q32 and 18p11.2. Proc Natl Acad Sci US A. 1999;96(10):5604-5609.

53. Shaw SH, Mroczkowski-Parker Z, Shekhtman T, et al. Linkage of a bipolar disorder susceptibility locus to human chromosome $13 \mathrm{q} 32$ in a new pedigree series. Mol Psychiatry. 2003;8(5):558-564.

54. Hattori E, Liu C, Badner JA, et al. Polymorphisms at the G72/G30 gene locus, on 13q33, are associated with bipolar disorder in two independent pedigree series. Am J Hum Genet. 2003;72(5):1131-1140.

55. Schumacher J, Jamra RA, Freudenberg J, et al. Examination of G72 and D-amino-acid oxidase as genetic risk factors for schizophrenia and bipolar affective disorder. Mol Psychiatry. 2004;9(2):203-207.

56. Chen YS, Akula N, Detera-Wadleigh SD, et al. Findings in an independent sample support an association between bipolar affective disorder and the G72/G30 locus on chromosome 13q33. Mol Psychiatry. 2004;9(1):87-92; image 5.

57. Prata D, Breen G, Osborne S, Munro J, St Clair D, Collier D. Association of DAO and G72(DAOA)/G30 genes with bipolar affective disorder. Am J Med Genet B Neuropsychiatr Genet. 2008;147B(6):914-917.

58. Williams NM, Green EK, Macgregor S, et al. Variation at the DAOA/ G30 locus influences susceptibility to major mood episodes but not psychosis in schizophrenia and bipolar disorder. Arch Gen Psychiatry. 2006;63(4):366-373.
59. Shi J, Badner JA, Gershon ES, Liu C. Allelic association of G72/ G30 with schizophrenia and bipolar disorder: a comprehensive metaanalysis. Schizophr Res. 2008;98(1-3):89-97.

60. Stefansson H, Sarginson J, Kong A, et al. Association of neuregulin 1 with schizophrenia confirmed in a Scottish population. Am J Hum Genet. 2003;72(1):83-87.

61. Green EK, Raybould R, Macgregor S, et al. Operation of the schizophrenia susceptibility gene, neuregulin 1, across traditional diagnostic boundaries to increase risk for bipolar disorder. Arch Gen Psychiatry. 2005;62(6):642-648.

62. Thomson PA, Christoforou A, Morris SW, et al. Association of Neuregulin 1 with schizophrenia and bipolar disorder in a second cohort from the Scottish population. Mol Psychiatry. 2007;12(1): 94-104.

63. Cassidy F, Roche S, Claffey E, McKeon P. First family-based test for association of neuregulin with bipolar affective disorder. Mol Psychiatry. 2006;11(8):706-707.

64. Sklar P, Smoller JW, Fan J, et al. Whole-genome association study of bipolar disorder. Mol Psychiatry. 2008;13(6):558-569.

65. Ferreira MA, O’Donovan MC, Meng YA, et al; Wellcome Trust Case Control Consortium. Collaborative genome-wide association analysis supports a role for ANK3 and CACNA1C in bipolar disorder. Nat Genet. 2008;40(9):1056-1058.

66. Smith EN, Bloss CS, Badner JA, et al. Genome-wide association study of bipolar disorder in European American and African American individuals. Mol Psychiatry. 2009;14(8):755-763.

67. Scott LJ, Muglia P, Kong XQ, et al. Genome-wide association and meta-analysis of bipolar disorder in individuals of European ancestry. Proc Natl Acad Sci U S A. 2009;106(18):7501-7506.

68. Psychiatric GWAS Consortium Bipolar Disorder Working Group. Large-scale genome-wide association analysis of bipolar disorder identifies a new susceptibility locus near ODZ4. Nat Genet. 2011;43(10):977-983.

69. Cichon S, Mühleisen TW, Degenhardt FA, et al; Bipolar Disorder Genome Study (BiGS) Consortium, Hamshere M, O’Donovan MC, et al. Genome-wide association study identifies genetic variation in neurocan as a susceptibility factor for bipolar disorder. Am J Hum Genet. 2011;88(3):372-381.

70. Green EK, Hamshere M, Forty L, et al; WTCCC, Jones IR, Craddock N. Replication of bipolar disorder susceptibility alleles and identification of two novel genome-wide significant associations in a new bipolar disorder case-control sample. Mol Psychiatry. Epub October 16, 2012.

71. Yosifova A, Mushiroda T, Kubo M, et al. Genome-wide association study on bipolar disorder in the Bulgarian population. Genes Brain Behav. 2011;10(7):789-797.

72. Bergen SE, O’Dushlaine CT, Ripke S, et al. Genome-wide association study in a Swedish population yields support for greater $\mathrm{CNV}$ and MHC involvement in schizophrenia compared with bipolar disorder. Mol Psychiatry. 2012;17(9):880-886.

73. Djurovic S, Gustafsson O, Mattingsdal M, et al. A genome-wide association study of bipolar disorder in Norwegian individuals, followed by replication in Icelandic sample. J Affect Disord. 2010;126(1-2): 312-316.

74. Hattori E, Toyota T, Ishitsuka Y, et al. Preliminary genome-wide association study of bipolar disorder in the Japanese population. Am J Med Genet B Neuropsychiatr Genet. 2009;150B(8):1110-1117.

75. Lee MT, Chen CH, Lee CS, et al. Genome-wide association study of bipolar I disorder in the Han Chinese population. Mol Psychiatry. 2011;16(5):548-556.

76. Cross-Disorder Group of the Psychiatric Genomics C, Smoller JW, Craddock N, et al. Identification of risk loci with shared effects on five major psychiatric disorders: a genome-wide analysis. Lancet. 2013;381(9875):1371-1379.

77. Seifuddin F, Mahon PB, Judy J, et al. Meta-analysis of genetic association studies on bipolar disorder. Am J Med Genet B Neuropsychiatr Genet. 2012;159B(5):508-518. 
78. Saunders EH, Scott LJ, McInnis MG, Burmeister M. Familiality and diagnostic patterns of subphenotypes in the National Institutes of Mental Health bipolar sample. Am J Med Genet B Neuropsychiatr Genet 2008;147B:18-26.

79. Lee HJ, Woo HG, Greenwood TA, Kripke DF, Kelsoe JR. A genomewide association study of seasonal pattern mania identifies NF1A as a possible susceptibility gene for bipolar disorder. J Affect Disord. 2013;145(2):200-207.

80. Goes FS, Hamshere ML, Seifuddin F, et al. Genome-wide association of mood-incongruent psychotic bipolar disorder. Transl Psychiatry. 2012;2:e180.

81. Meier S, Mattheisen M, Vassos E, et al; Bipolar Disorder Genome Study (BiGS) Consortium, Nöthen MM, Cichon S. Genome-wide significant association between a 'negative mood delusions' dimension in bipolar disorder and genetic variation on chromosome 3q26.1. Transl Psychiatry. 2012;2:e165.

82. Dizier MH, Etain B, Lajnef M, et al. Genetic heterogeneity according to age at onset in bipolar disorder: a combined positional cloning and candidate gene approach. Am J Med Genet B Neuropsychiatr Genet. 2012;159B(6):653-659.

83. Belmonte Mahon P, Pirooznia M, Goes FS, et al; Bipolar Genome Study (BiGS) Consortium, The Wellcome Trust Case Control Consortium Bipolar Disorder Group, Depaulo JR Jr, et al. Genome-wide association analysis of age at onset and psychotic symptoms in bipolar disorder. Am J Med Genet B Neuropsychiatr Genet. 2011;156B(3):370-378.

84. Perlis RH, Huang J, Purcell S, et al; Wellcome Trust Case Control Consortium Bipolar Disorder Group, Craddock N, Sklar P, Smoller JW. Genome-wide association study of suicide attempts in mood disorder patients. Am J Psychiatry. 2010;167(12):1499-1507.

85. Willour VL, Seifuddin F, Mahon PB, et al. A genome-wide association study of attempted suicide. Mol Psychiatry. 2012;17(4):433-444.

86. Kerner B, Lambert CG, Muthén BO. Genome-wide association study in bipolar patients stratified by co-morbidity. PLoS One. 2011;6(12):e28477.

87. Phillips ML, Ladouceur CD, Drevets WC. A neural model of voluntary and automatic emotion regulation: implications for understanding the pathophysiology and neurodevelopment of bipolar disorder. Mol Psychiatry. 2008;13(9):829, 833-857.

88. Liu X, Akula N, Skup M, Brotman MA, Leibenluft E, McMahon FJ. A genome-wide association study of amygdala activation in youths with and without bipolar disorder. JAm Acad Child Adolesc Psychiatry. 2010;49(1):33-41.
89. LeBlanc M, Kulle B, Sundet K, et al. Genome-wide study identifies PTPRO and WDR72 and FOXQ1-SUMO1P1 interaction associated with neurocognitive function. J Psychiatr Res. 2012;46(2): 271-278.

90. Wang F, McIntosh AM, He Y, Gelernter J, Blumberg HP. The association of genetic variation in CACNA1C with structure and function of a frontotemporal system. Bipolar Disord. 2011;13(7-8):696-700.

91. Soeiro-de-Souza MG, Bio DS, Dias VV, Vieta E, Machado-Vieira R, Moreno RA. The CACNA1C risk allele selectively impacts on executive function in bipolar type I disorder. Acta Psychiatr Scand. Epub February 14, 2013 .

92. Zhang Q, Shen Q, Xu Z, et al. The effects of CACNA1C gene polymorphism on spatial working memory in both healthy controls and patients with schizophrenia or bipolar disorder. Neuropsychopharmacology. 2012;37(3):677-684.

93. Carless MA, Glahn DC, Johnson MP, et al. Impact of DISC1 variation on neuroanatomical and neurocognitive phenotypes. Mol Psychiatry. 2011;16(11):1096-1104, 1063.

94. Li M, Luo XJ, Rietschel M, et al; MooDS Bipolar Consortium, Strohmaier J, Breuer R, et al; The Swedish Bipolar Study Group, Backlund L, Frisén L, et al; The Alzheimer's Disease Neuroimaging Initiative; ENIGMA Consortium; CHARGE Consortium, Su B. Allelic differences between Europeans and Chinese for CREB1 SNPs and their implications in gene expression regulation, hippocampal structure and function, and bipolar disorder susceptibility. Mol Psychiatry. 2013. Epub.

95. International Schizophrenia C, Purcell SM, Wray NR, et al. Common polygenic variation contributes to risk of schizophrenia and bipolar disorder. Nature. 2009;460(7256):748-752.

96. Schulze TG, Akula N, Breuer R, et al; The Bipolar Genome Study, McMahon FJ. Molecular genetic overlap in bipolar disorder, schizophrenia, and major depressive disorder. World J Biol Psychiatry. Epub March 9, 2012.

97. Whalley HC, Papmeyer M, Sprooten E, et al. The influence of polygenic risk for bipolar disorder on neural activation assessed using fMRI. Transl Psychiatry. 2012;2:e130.

98. Whalley HC, Sprooten E, Hackett S, et al. Polygenic risk and white matter integrity in individuals at high risk of mood disorder. Biol Psychiatry. 2013;74(4):280-286.
Neuropsychiatric Disease and Treatment

\section{Publish your work in this journal}

Neuropsychiatric Disease and Treatment is an international, peerreviewed journal of clinical therapeutics and pharmacology focusing on concise rapid reporting of clinical or pre-clinical studies on a range of neuropsychiatric and neurological disorders. This journal is indexed on PubMed Central, the 'PsycINFO' database and CAS.

\section{Dovepress}

The manuscript management system is completely online and includes a very quick and fair peer-review system, which is all easy to use. Visit http://www.dovepress.com/testimonials.php to read real quotes from published authors. 